\title{
Re-evaluation of heat precipitation method for plasm
fibrinogen estimation: effect of abnormal proteins and plasma viscosity
}

\author{
LEOPOLD DINTENFASS AND SYLVIA KAMMER \\ From the Haemorheology Unit and Medical Research, Sydney Hospital, and Department of Medicine, \\ University of Sydney, Australia
}

SYNOPSIS The heat precipitation method (Aberdeen method) was compared with the Ratnoff and Menzie method of fibrinogen assay in 320 donors, including normals and patients suffering from $\vec{\omega}$ malignant melanoma, renal failure, hypertension, multiple myeloma, etc. Excellent correlation 0 $(\mathrm{r}=0.8287, \mathrm{P}<0.0000001)$ was found between these two methods. However, on some occasions 은 individual low results were obtained by the Aberdeen method in the presence of cryoglobulins or $\vec{T}$ excessively high plasma viscosity. The latter effect was tested also by additions of albumin, glucose, $\mathbb{D}$ and dextrans.

Millar et al (1971) reported on the use of a heatprecipitation method of fibrinogen estimation (based on the studies of Foster et al (1959) and Low et al (1967)) and showed that it compares favourably with standard haematological methods. They noted that the value obtained by the heat precipitation method (henceforth referred to as the 'Aberdeen' method) might be higher than that obtained by the usual methods (eg, Ratnoff and Menzie, 1951); they quoted also the work of Collier et al (1951), showing that abnormal plasma proteins are precipitated by heat and tend to increase the apparent fibrinogen level.

Our intention was to carry out a comparative study of fibrinogen estimations by means of the Aberdeen method and the Ratnoff and Menzie method, and to explore the effects, if any, of different anticoagulants, abnormal proteins, and high molecular weight dextran on the results obtained by these two methods. As will be shown, an excellent correlation is obtained between these two methods. However in some circumstances one or other method shows slight superiority, although in the presence of abnormal proteins the Aberdeen method gives reduced (and not increased) results.

It must be stressed that the importance of fibrinogen assay in patients suffering from cardiovascular disorders becomes more widely appreciated. This follows realization that fibrinogen might play a role

Received for publication 25 July 1975 perhaps more important than that of lipids. This बि especially evident in its effect on elevation of bloed viscosity (Dintenfass, 1974; Dintenfass and Forbes, 1975; Dormandy et al, 1973; Hart et al, 1971). More recent clinical work has indicated that a decrease of fibrinogen level (by infusion of Ancrod) leads to an $\stackrel{\square}{\square}$ improvement in the patient's condition (Dormandy et al, 1974; Ehrly, 1975).

\section{Methods}

HEAT-PRECIPITATION (ABERDEEN) TECHNIQUE OF FIBRINOGEN ASSAY Following the method of Millar et al (1971), blood obtained by clean venepuncture and anticoagulated with sequestrene (EDTA) or potassium oxalate was drawn into microhaematocrit tubes and spun in a을 Hawksley microhaematocrit centrifuge for 5 D minutes. The tubes were placed in a waterbath at $56^{\circ} \mathrm{C}$ for 3 minutes and then centrifuged again for a N further 3 minutes. Precipitated fibrinogen was packed $\%$ on top of the buffy coat. Using the usual micro- $N$ haematocrit vernier and a stereomicroscope it was $\mathrm{N}$ possible to define the interface between the buffy coat 0 and the fibrinogen layer. The amount of fibrinogeno in the plasma is given by a ratio of fibrinogen deposit $\bar{\Phi}$ length (AB) to fibrinogen plus plasma length (AC) $\stackrel{\oplus}{+}$ multiplied by 100 , thus giving results as $\mathrm{ml} / 100 \mathrm{ml}$ (according to Millar et al, 1971).

Using the above scale, a slope of a comparative plot of Aberdeen and of Ratnoff and Menzie results $\stackrel{\mathbb{\varrho}}{\stackrel{D}{\varrho}}$ 
shows values from 0.90 to 1.08 , that is, a mean slope of $45^{\circ}$. Consequently, we considered it more convenient to use the following modification. We converted $\mathrm{ml} \%$ to $\mathrm{g} \%$ (as $1: 1$ ratio) and at first expressed values obtained in $\mathrm{mg} \%$; however, the numerical values were 10 times too high (eg, $5 \mathrm{ml} \%$ $\cong 5 \mathrm{~g} \%=5000 \mathrm{mg} \%$, while the true reading should have been $500 \mathrm{mg} \%$ ). In other words, there is an additional coefficient, or factor, in the calculation of fibrinogen concentration by the heat-precipitation method. It might be due to the fact that the precipitated fibrinogen required a 10 times higher volume than compact solid fibrinogen; but it is rather unusual, even if convenient, that this factor should be 10 and not any number other than 10 . Nevertheless, by dividing the experimental values by 10 it was possible to plot the results of the heatprecipitation method on a scale identical with that used for the Ratnoff and Menzie method.

THROMBIN-CLOTTABLE FIBRINOGEN ASSAY

A quantitative method was based on Ratnoff and Menzie (1951) as modified by Dacie and Lewis (1968). Fibrinogen in plasma was converted into fibrin by the addition of thrombin. Fibrin was collected on glass beads, washed, and boiled with sodium hydroxide, and its tyrosine content was estimated using Folix-Ciocalteu phenol reagent. Results were read in a spectrophotometer at a wavelength of $650 \mathrm{~nm}$, using a $1 \mathrm{~cm}$ light path in a glass cuvette.

\section{ANTICOAGULANTS}

The effect of potassium oxalate and EDTA (sequestrene) was evaluated in the Aberdeen method of fibrinogen assay.

\section{ABNORMAL PROTEINS}

Abnormal proteins, including cryoglobulins and myeloma proteins, were studied by using the plasma of patients suffering from the respective disorders, and their role on the accuracy of the Aberdeen method was evaluated.

\section{DEXTRAN SOLUTIONS}

During the first part of the study stock solutions of $2 \%$ and $5 \%$ concentrations of 280000 molecular weight (Type 200C, Sigma Chemical Co, St. Louis, Miss, USA) were used in $2: 1$ or $4: 1$ volume ratios with blood samples. Plasma fibrinogen was assayed in the original blood samples using the Ratnoff and Menzie method; all subsequent samples, and original samples, were assayed by the Aberdeen method. In the latter part of the study, when the effect of plasma viscosity was to be investigated, dextran solutions of concentrations up to $50 \%$ were used.
PLASMA VISCOSITY

The effect of plasma viscosity was studied by the addition of high concentrations of glucose, albumin or dextran to blood samples before fibrinogen assay by the Aberdeen method. Viscosity of expanded plasma was determined using the Coulter Automatic Capillary Viscometer of $\mathbf{0 . 3} \mathrm{mm}$ diameter capillary.

\section{BLOOD SAMPLES}

Blood samples were obtained from patients and donors by venepuncture. The patients included those suffering from malignant melanoma, hypertension, renal failure, ischaemic heart disease, multiple myeloma, etc., a total of 320 individual donors. Subsequent studies on an additional 500 patients showed an identical pattern.

\begin{tabular}{|c|c|c|c|}
\hline$a$ & $b$ & $r$ & $\mathbf{P}$ \\
\hline \multicolumn{4}{|c|}{$\begin{array}{l}\text { (a) Aberdeen method: comparison of EDTA }(n=56) v \text { potassium } \\
\text { oxalate }(n=56)\end{array}$} \\
\hline $\begin{array}{l}\text { (b) Comparison of Ratnoff } \\
\text { 1 }(\mathrm{n}=152) v(\mathrm{n}=152)\end{array}$ & $\begin{array}{r}0.937 \\
f \text { and }\end{array}$ & $\begin{array}{l}0.9672 \\
\text { zie metho }\end{array}$ & $\begin{array}{l}<0.001 \\
v \text { Aberdeen method }\end{array}$ \\
\hline $2 *(\mathrm{n}=319) v(\mathrm{n}=319)$ & 0.902 & 0.8187 & $<0.000001$ \\
\hline 51.8 & 0.827 & 0.8287 & $\ll 0.0000001$ \\
\hline
\end{tabular}

Table I Linear regressions and correlations for fibrinogen assays carried out by different methods

$* S_{y, x}=64 \cdot 9$. Note: $a$ and $b$ are coefficients of the linear regression equation: $y=a+b x$.

\begin{tabular}{llll}
\hline Patient & Date & \multicolumn{2}{l}{ Results of Fibrinogen Assay } \\
\cline { 3 - 4 } & & Aberdeen & Ratnoff and Menzie \\
\hline EV & 5 July '72 & 125 & 639 \\
RJ & 15 Sept.'72 & 225 & 358 \\
WN & 18 Jan. '73 & 410 & 618 \\
SA & 1 Feb. '73 & 243 & 395 \\
NK & 22 Feb. '73 & 533 & 910 \\
JK & 25 May'73 & 198 & 557 \\
\hline
\end{tabular}

Table II Abnormally low results of fibrinogen level obtained by the Aberdeen method

\begin{tabular}{lllll}
\hline Abnormal Proteins & \multicolumn{3}{c}{ Fibrinogen Concentration $(m g \%)$} \\
\cline { 2 - 5 } & \multicolumn{5}{c}{$\begin{array}{c}\text { Aberdeen } \\
\text { Method }\end{array}$} & Calculated \\
& $n$ & $\overline{\mathrm{x}} \pm S D$ & $\overline{\mathrm{x}} \pm S D$ & $\mathrm{P}$ \\
\hline Cryoproteins & $12(24)$ & $413 \pm 70$ & $637 \pm 51$ & $<0.001$ \\
Myeloma protein & $12(24)$ & $274 \pm 18$ & $468 \pm 43$ & $\ll 0.001$ \\
& $12(24)$ & $343 \pm 53$ & $369 \pm 11$ & $c 0.70$ \\
& $8(16)$ & $245 \pm 42$ & $269 \pm 46$ & $c 0.40$ \\
\hline
\end{tabular}

Table III Effect of cryoglobulins and myeloma proteins on accuracy of Aberdeen method (using reconstructed blood of known fibrinogen level) 


\section{Results}

The results of this study are shown in tables I to V.

Table I shows the correlation between the Aberdeen and Ratnoff and Menzie methods of plasma fibrinogen assay, and between EDTA and potassium oxalate used as anticoagulants during the Aberdeen method of assay. The correlation coefficient between series in which EDTA or potassium oxalate was used as anticoagulant in the Aberdeen assay was very high $(r=0.9672)$, the corresponding significance level being well below 0.001 .

A comparison between the Aberdeen and the Ratnoff and Menzie methods was carried out'on two series of patients, both showing very high correlation coefficients (above 0.81) and extremely high significance levels (well below 0.000 001). According to any statistical measure these two methods are analogous in respect of values obtained for plasma fibrinogen. Nevertheless we noted on some occasions that values for fibrinogen were lower when obtained by the Aberdeen method (table II) and decided to explore the reason for the decrease of value in the fibrinogen assay. By addition of plasma from patients suffering from multiple myeloma or cryo globulinaemia (usually in 1:1 ratio of volumes), we investigated the effect of abnormal proteins (table III). The results show clearly that while myelom protein does not affect the accuracy of the Aberdeer method, cryoglobulin decreases the fibrinogen value at significance levels below 0.001 .

As the high molecular weight compounds coul $\vec{\Phi}$ affect the assay, dextran (molecular weight $280000 \mathrm{~J}$ was used in three series of blood samples (table IV) An addition of $2 \%$ and $5 \%$ dextran solutions in $1: 1 \frac{8}{8}$ $2: 1$, and $4: 1$ volume ratios indicated that any effecin on assay was not actually due to the presence of thes dextran molecule per se; rather it appeared to relat to the type of patient. While melanoma patients (oro more exactly, their blood samples) and renal patients showed no changes in the assay due to dextran, group $\mathrm{C}$, composed of leukaemia, lymphoma, and throm



Table IV Effect of high molecular weight dextran addition on accuracy of Aberdeen method (using reconstructed blood of known fibrinogen level)

${ }^{1}$ Calculation based on known (after Ratnoff and Menzie method) concentration of fibrinogen in original plasma.

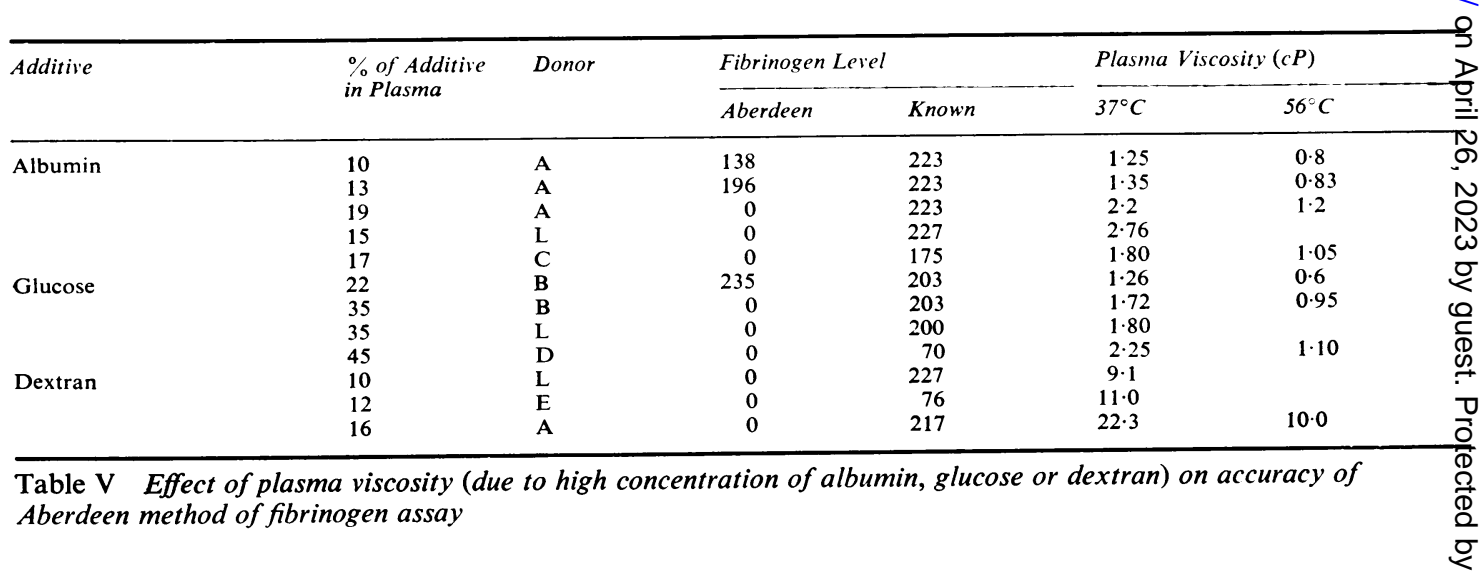


bocytopenia patients, did show a change in fibrinogen assay.

The question therefore arose whether any abnormality in fibrinogen assay by the Aberdeen method might be influenced by the viscosity of plasma. Elevation of plasma viscosity was induced by additions of high concentration solutions of albumin, glucose, or dextran (table V). This series showed clearly that at albumin concentrations of 17 and $19 \%$ in plasma, fibrinogen assay showed zero values. At glucose concentrations above $35 \%$ in plasma, fibrinogen assay also showed zero values. An analogous situation was shown by dextran at $14 \%$ and higher concentrations.

\section{Discussion}

Determination of fibrinogen is of importance in cardiovascular and malignant diseases, as fibrinogen affects a number of blood viscosity factors, including aggregation of red cells, viscosity of plasma, and apparent viscosity and viscoelasticity of venous and arterial thrombi. The role of fibrinogen is not superseded but only complemented by the role of fibrinfibrinogen split products in disorders including myocardial infarction and intravascular coagulation (McNicol et al, 1969; Okuno and Nelson, 1974; Zetterqvist, 1971). In the hyperviscosity syndromes (Dintenfass, 1971) or in liver malfunction (Wardle, 1974) a simple and rapid method of fibrinogen assay is advantageous.

The well-established method of Ratnoff and Menzie (1951) is accurate if complex and time consuming. While some new and more rapid methods have recently been described (Natelson and Dooley, 1974; Roberts et al, 1973), there is justification for using the heat-precipitation method of Millar et al (1971). Our experimental data show this method to be equivalent in accuracy to the Ratnoff and Menzie method, the significance limit being below 0.0000001 . This correlation was obtained while absolute values were ascribed to the heat-precipitation method; that is, the degree of packing of precipitated fibrinogen is constant under nearly all conditions. If such packing were different in different blood samples, such a high degree of correlation could not have been obtained. Both the potassium oxalate and sequestrene (EDTA) show similar results, the correlation between series based on these two anticoagulants showing $\mathrm{r}=0.9672$ and $\mathrm{P}<$ 0.001 .

There are, of course, some exceptions. On a few occasions a distinct difference was found in values of fibrinogen when assayed by the Aberdeen and Ratnoff and Menzie methods. The former showed lower values of fibrinogen only under the following conditions:

(1) in the presence of cryoglobulins;

(2) when plasma viscosity is abnormally high (that is, when it is higher than $1.6 \mathrm{cP}$ at $37^{\circ} \mathrm{C}$, the normal value being about $1.2 \mathrm{cP}$ ).

A degree of doubt is present when patients suffer from leukaemia, lymphosarcoma or thrombocytopenia.

The artificial systems studied did not modify the values of fibrinogen assay or packing of precipitate through changes in the density of the supernatant but only through its viscosity. The density of the supernatant was increased in the presence of albumin and decreased in the presence of dextran. While it is known that dextran affects the structure of fibrin clot (Muzaffar et al, 1972), its effect on fibrinogen assay by the heat-precipitation method becomes apparent only when the supernatant viscosity is above $1.6 \mathrm{cP}$. Whenever plasma viscosity (or supernatant viscosity) is increased above this value by the addition of albumin, glucose or dextran, it is not even possible to obtain a reading of the precipitate volume. It should be stressed that the amounts of these additives required for an increase of plasma viscosity above the critical level are excessive for the usual clinical conditions.

These excessive amounts of additives were used only in order to explain the low fibrinogen assay in a few exceptional patients and thus to gain confidence that the Aberdeen method is suitable for assays of fibrinogen in cardiovascular and renal patients and in the majority of other patients, with the exception of cryoglobulin and paraprotein dyscrasias.

In summary, we investigated the Aberdeen method for hidden flaws, and for reasons why and when such flaws might occur. It appears that the Aberdeen method should be recommended.

We are indebted to Miss Beverley Hewitt, Haematology Department of Sydney Hospital, for determinations of fibrinogen by the Ratnoff and Menzie method.

This study was supported by grants from the National Health and Medical Research Council of Australia, and from the Sydney Hospital Medical Research Fund.

\section{References}

Collier, F. C., Reich, A., and King, J. W. (1951). Multiple myeloma. New Engl. J. Med., 245, 969-971.

Dacie, J. V. and Lewis, S. M. (1968). Practical Haematology, 4th ed., pp. 285-287.

Dintenfass, L. (1971). Blood Microrheology-Viscosity Factors in Blood Flow, Ischaemia and Thrombosis. Butterworths, London. 
Dintenfass, L. (1974). Significant effect of ABO blood groups on the aggregation of red cells in patients with diabetes mellitus. Role of fibrinogen and serum proteins. Microvasc. Res., 7, 326-341.

Dintenfass, L. and Forbes, C. D. (1975). Effect of fibrinogen on aggregation of red cells and on apparent viscosity of artificial thrombi in haemophilia, myocardial infarction, thyroid disease, cancer and control systems: effect of ABO blood groups. Microvasc. Res., 9, 107-118.

Dormandy, J. A., Gutteridge, J. M. C., Hoare, E. and Dormandy, T. L. (1974). Effect of clofibrate on blood viscosity in intermittent claudication. Brit. med. J., 4, 259262.

Dormandy, J. A., Hoare, E., Colley, J., Arrowsmith, D. E., and Dormandy, T. L. (1973). Clinical, haemodynamic, rheological, and biochemical findings in 126 patients with intermittent claudication. Brit. med. J., 4, 576-581.

Ehrly, A. M. (1975). Improvement of the microcirculatory properties of blood in patients with vascular diseases treated with Ancrod. 1st World Congress for Microcirculation, Toronto (June 15-20), Abstract No. 278.

Foster, J. B. T., De Natale, A., and Dotti, L. B. (1959). Determination of plasma fibrinogen by means of centrifugation after heating. Amer. J. clin. Path., 31, 42-45.

Frick, P. G. (1955). Inhibition of conversion of fibrinogen to fibrin by abnormal proteins in multiple myeloma. Amer.J. clin. Path., 25, 1263-1273.

Hart, A., Thorp, J. M., and Cohen, H. (1971). Lipoprotein and fibrinogen studies in diabetes. Postgrad. med. J., June suppl., pp. 453-439.

Korsan-Bengtsen, K., Wilhelmsen, L., and Tibblin, G. (1972). Blood coagulation and fibrinolysis in a random sample of 788 men 54 years old. I. Correlations between the variables of clotting and fibrinolysis. Thrombos. Diathes. haemorrh. (Stuttg.), 28, 89-108.

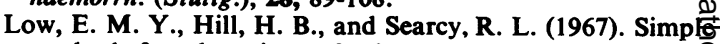
method for detection of abnormal plasma fibrinoge? levels. Amer. J. clin. Path., 47, 538-540.

McNicol, G. P., Wilson, P. A., and Douglas, A. S. (1969) The influence of fibrinogen breakdown products on the aggregation of platelets. In Therapeutische und expert mentelle Fibrinolyse, edited by V. Hiemeyer, pp. 169-17民. F. K. Schattauer, Stuttgart and New York.

Millar, H. R., Simpson, J. G., and Stalker, A. L. (1971). A evaluation of the heat precipitation method for plasm 8 fibrinogen estimation. J. clin. Path., 24, 827-830.

Muzaffar, T. Z., Stalker, A. L., Bryce, W. A. J., and DhallD. P. (1972). Structural alterations in fibrin clots with dextran. Thrombos. Diathes. haemorrh. (Stuttg.), 28, 257 267.

Natelson, E. A. and Dooley, D. F. (1974). Rapid determins tion of fibrinogen by thrombokinetics. Amer.J. clin. Path 61, 828-833.

Okuno, T. and Nelson, C. (1974). Value of determination of serum fibrin-fibrinogen degradation products in acute myocardial infarction. Amer. J. clin. Path., 61, 155-159. $\vec{\omega}$

Ratnoff, O. D. and Menzie, C. (1951). A new method for the determination of fibrinogen in small samples of plasma J. Lab. clin. Med., 37, 316-320.

Roberts, P. S., Regelson, W., and Kingsbury, B. (1973) Determination of fibrinogen in normal human plasma if the presence and absence of anticoagulants. J. Lab. clire Med., 82, 822-828.

Wardle, E. N. (1974). Fibrinogen in liver disease. Arch Surg., 109, 741-746.

Zetterqvist, E. (1971). Fibrinogen degradation products in experimental intravascular coagulation. Acta phy fo? scand., 82, 289-299. 